NBER WORKING PAPERS SERIES

EXCHANGE RATE VOLATILITY AND

INTERNATIONAL PRICES

\author{
Robert C. Feenstra \\ Jon D. Kendall
}

Working Paper No. 3644

NATIONAL BUREAU OF ECONOMIC RESEARCH

1050 Massachusetts Avenue

Cambridge, MA 02138

March 1991

This paper is part of NBER's research program in International studies. Any opinions expressed are those of the authors and not those of the National Bureau of Economic Research. 
NBER Working Paper \#3644 March 1991

\title{
EXCHANGE RATE VOLATILITY AND \\ INTERNATIONAL PRICES
}

\begin{abstract}
We examine how exchange rate volatility affects exporter's pricing decisions in the presence of optimal forward covering. By taking account of forward covering, we are able to derive an expression for the risk premium in the Ereign exchange market. which is then estimated as a generalized ARCH model to obtain the time-dependent variance of the exchange rate. Our theory implies a connection between the estimated risk premium equation, and the influence of exchange rate volatility on export prices. In particular, we argue that if there is no risk premium, then exchange rate variance can only have a negative impact on export prices. In the presence of a risk premium, however, the effect of exchange rate variance on export prices is ambiguous, and may be statistically insignificant with aggregate data. These resuits are supported using data on aggregate U.S. imports and exchange rates of the dollar against the pound, yen and mark.

Robert C. Feenstra Department of Economics University of California Davis, California 95616

Jon D. Kendall Department of Economics University of Tasmania G.P.O. BOX $252 \mathrm{C}$ Hobart, Tasmania 7001 Australia
\end{abstract}




\section{Introduction}

The sustained rise of the US dollar from 1981 to early 1985, and subsequent fall to the present, has contributed to interest in "pass-through" relationships between changes in exchange rates and traded goods prices. Recently, researchers have also begun to explore how volatility of the exchange rate may influence traded goods prices. Authors including Hooper and Kolhlagen (1978), Akhtar and Kilton (1984), Gotur (1985) Cushman (1983,1986), and Mann (1989) have estimated pass-through equations which incorporate some measure of exchange rate volatility: the goal is to see how variance in the exchange rate affects traded goods prices. ${ }^{1}$ This paper extends earlier analysis - building especially on Mann (1989) - by examining how exchange rate volatility affects exporter's pricing decisions in the presence of optimal forward covering, and by integrating the estimation of exchange rate pass-through, variance and the risk premium in foreign exchange markets. ${ }^{2}$

By taking account of forward covering, we are able to derive an expression for the risk premium in the foreign exchange markets, which is then estimated as a generalized ARCH model to obtain the time-dependent variance of the exchange rate. ${ }^{3}$ Our theory implies a connection between the estimated risk premium equation, and the influence of exchange rate volatility on export prices. In particular, we argue that if there is no risk premium (so that the forward rate equals the expected future spot rate), then exchange rate variance can only have a negative impact

1 These papers - like ours - stop short of considering how volatility of the exchange rate can affect its equilibrium level, though this may be the ultimate question of interest. Krugman (1989) includes a discussion of how volatility may influence the equilibrium exchange rate, while Hodrick (1989) estimates a model where volatility of the money supply and GNP is a potential determinant of the exchange rate. This point is discussed further in in section 7.

2 It should be noted that our qualitative results in section 2 are the same as those in Mann (1989), though she does not consider forward covering. Theoretical analyses of optimal forward covering include Ethier (1973), Baron (1976a), Kawai and Zilcha (1986) and Eldor and Zilcha (1987).

$3 \mathrm{ARCH}$ (autoregressive conditional heteroscedasticity) techniques have been applied to the foreign exchange market by Baillie and Bollerslev (1987a,b), Hsieh (1988), and the various references discussed in section 5 . 
on export prices. In the presence of a risk premium, however, the effect of exchange rate variance on export prices is ambiguous, and may be statistically insignificant with aggregate data.

In sections 2 and 3 we present a model highlighting the differing effects of exchange rate variance on exporters depending on the currency of invoice. A risk-averse exporter setting price in the currency of the importing country will raise its price the higher is variance. The opposite is true for an exporter setting price in its own currency, where a higher variance results in a lower price. However, a firm which sets price in the importing country's currency can cover in the foreign exchange market, reducing the positive influence of variance. The extent to which it covers hinges on the difference between the forward price of the importing country's currency and its expected value, as discussed in section 4 .

In section 5 we estimate the variance of the exchange rate using an ARCH-in-Mean model for the pound, yen and mark against the US dollar. A significant negative time-varying risk premium is found for the yen but not for either the pound or mark. In section 6 we estimate a pass-through equation incorporating the exchange rate variance. The pass-through relation is reformulated as a Purchasing Power Parity (PPP) equation, embedded in an error-correction mechanism. Quarterly aggregate data (including exchange rate variance estimates from section 5) from 1975.1 to 1988.1 for the United Kingdom, Japan and Germany are used to estimate the three PPP-form equations. Variance elasticities are significant and negative for the United Kingdom and Germany but not for Japan, supporting the idea that exporting firms pricing in US dollars are able to cover adequately in pounds and marks but not in yen. We also present the implied estimates of the pass-through equation for these countries. Conclusions are given in section 7 .

\section{Pass-Through Models}

Two factors determine the impact of exchange rate variance on pass-through, namely, the currency in which the exporter sets price and the availability of forward exchange rate contracts. Numerous authors have examined the question of the currency in which exporting firms set 
price. ${ }^{4}$ Studies which have examined the optimal choice of invoicing strategy include those by Baron (1976b) and Giovannini (1988), with the result that the optimal choice is very sensitive to properties of the demand function. We shall consider invoicing in either the currency of the exporter or the importing country. Recent evidence from Page (1981) suggests that around 85 per cent of US imports and 95 per cent of US exports are denominated in US dollars. 5 However, the percentages are lower for U.S. trade with a number of the industrialised countries, so even for sales to the U.S. consideration should be made for invoicing in both domestic and foreign currencies.

\subsection{Invoicing in the Importing Country's Currency}

In this section we suppose that the firm chooses its price in the importing country's (domestic) currency. The model we shall use is similar to Feenstra (1989), except that the firm is assumed to be risk averse. The spot price of foreign exchange in terms of domestic currency, $s$, is stochastic. Since the exporter cannot adjust price to every exchange-rate movement, the revenues received are uncertain (the firm's ability to hedge is discussed in section 4). The demand for imports is given by $x(p, q, I)$, where prices of the imported and domestic import-competing goods are represented by $p$ and $q$, respectively, and $I$ is consumer income or expenditure. ${ }^{6}$ The firm maximises expected utility of profits in its own (foreign) cursency:

4 In his studies of payments habits of Sweden, Grassman $(1973,1976)$ drew attention to the fact that the US dollar was not the exclusive currency of payment between industrialised countries, though he found a tendency for US currency to be used by firms exporting to the US.

5 Page (1981) also notes that 90 and 60 percent of Japanese imports and exports, respectively, are denominated in US dollars. Forty and 80 per cent of German imports and exports, respectively, are denominated in marks, while 40 and 75 percent of UK imports and exports are invoiced in pounds.

6 Note that the prices of domestic goods $q$ could certainly be a vector, but for convenience we shall treat it as a scalar aggregate. Since the exporting firm treats $q$ as exogenous, it is engaged in Bertrand competition. 


$$
\max _{p} E\left(u\left[\operatorname{spx}(p, q, I)-x(p, q, I) w^{*}\right]\right)
$$

where $\mathrm{E}$ denotes expected value; $\mathrm{u}$ is the firm's utility function; and the cost function is linear with $w^{*}$ denoting an aggregate of foreign factor prices in foreign currency. All variables except $s$ are deterministic.

Let $e=E(s)$, where e denotes the expected exchange-rate, and let $\pi^{*}=\left(s p-w^{*}\right) \times(p, q, I)$ denote profits in the exporting country's currency. Then $u\left(\pi^{*}\right)$ may be approximated by a second order Taylor expansion about expected profits as:

$$
u\left(\pi^{*}\right) \approx u\left(E \pi^{*}\right)+u^{\prime}\left(E \pi^{*}\right)\left(\pi^{*}-E \pi^{*}\right)+\frac{1}{2} u^{\prime \prime}\left(E \pi^{*}\right)\left(\pi^{*}-E \pi^{*}\right)^{2}
$$

Substituting equation (2) into equation (1) and noting that $E\left(\pi^{*}-E \pi^{*}\right)=0$, we obtain:

$$
\max _{\mathrm{p}} u\left(E \pi^{*}\right)+\frac{1}{2} u^{\prime \prime}\left(E \pi^{*}\right) \operatorname{var}\left(\pi^{*}\right)
$$

Assuming that $\mathrm{u}^{\prime \prime}\left(\mathrm{E} \pi^{*}\right)$ is constant ${ }^{7}$ allows one to derive the first order condition as:

$$
u^{\prime}\left(E \pi^{*}\right)\left[e x+\left(e x-w^{*}\right) \frac{\partial x}{\partial p}\right]+\frac{1}{2} u^{\prime \prime} \frac{d}{d p} \operatorname{var}\left(\pi^{*}\right)=0
$$

Let $-\eta \equiv(d x / d p)(p / x)$ and $R_{u} \equiv-\left[u^{\prime \prime}\left(E \pi^{*}\right) / u^{\prime}\left(E \pi^{*}\right)\right]$, where $\eta$ is the elasticity of demand and $R_{\mathrm{u}}$ is an Arrow-Pratt absolute measure of risk-aversion. Dividing through by $\mathrm{e}(\partial \times / \partial \mathrm{p})$ and $u^{\prime}$, equation (4) may then be rearranged as:

$$
p\left(1-\frac{1}{\eta}\right)-\left(\frac{w^{*}}{e}\right)=\frac{1}{2} R_{u}\left[\frac{\frac{d}{d p} \operatorname{var}\left(\pi^{*}\right)}{e \frac{\partial x}{\partial p}}\right]
$$

7 Thus, our analysis is exact for a quadratic utility function u. 
The left side of (5) may be interpreted as the difference between marginal revenue and marginal cost. Notice that the signs of $R_{\mathrm{u}}$ (positive) and $\partial \mathrm{x} / \partial \mathrm{p}$ (negative) are known, leaving the sign of $d / d p\left[\operatorname{var}\left(\pi^{*}\right)\right]$ to decide if marginal revenue is less than or greater than marginal cost. Since $\operatorname{var}\left(\pi^{*}\right)=(\mathrm{px})^{2} \sigma_{\mathrm{s}}^{2}$, we have that:

$$
\frac{d}{d p} \operatorname{var}\left(\pi^{*}\right)=2(p x) \sigma_{s}^{2} p\left[1-\frac{1}{\eta}\right] \frac{\partial x}{\partial p}<0
$$

since the exporing firm sets price in the elastic portion of the demand curve (i.e $\eta>1$ ). Thus, $\operatorname{var}\left(\pi^{*}\right)$ is reduced by raising price $p$. It follows from (5) that the firm will set price where marginal revenue is greater than marginal cost:

$$
\mathrm{p}\left(1-\frac{1}{\eta}\right)-\left(\frac{\mathrm{w}^{*}}{\mathrm{e}}\right)=\mathrm{R}_{\mathrm{u}}(\mathrm{epx}) \mathrm{p}\left(1-\frac{1}{\eta}\right)\left[\sigma_{\mathrm{s}}^{2} / \mathrm{e}^{2}\right]>0
$$

The wedge between marginal revenue and marginal cost is increased with greater variance or risk aversion on the right of (7). This means that price is also raised with more variance or risk aversion. The reason is that the higher price reduces revenue and therefore the variance of profits in the objective function (3).

\subsection{Invoicing in the Exporting Country's Currency}

The maximisation problem confronting an exporting firm which sets price in its own currency is similar to that above except that now profit is maximised by choosing $\mathrm{p}^{*}$ :

$$
\max _{\mathrm{p}^{*}} u\left(E \pi^{*}\right)+\frac{1}{2} u^{\prime \prime}\left(E \pi^{*}\right) v \operatorname{ar}\left(\pi^{*}\right)
$$


where $\pi^{*}=\left(p^{*}-w^{*}\right) \times\left(p^{*} / s, q, I\right)$ and $p^{*} / s$ is random. Again the firm sets price before the exchange rate is known but, unlike the case where the exporter sets price in the domestic currency, revenues now are uncertain due to random fluctuations in import demand.

Again treating $\mathrm{u}^{\prime \prime}\left(\mathrm{E} \pi^{*}\right)$ as constant, the first-order condition for (8) is:

$$
u^{\prime}\left[E x+\left(p^{*}-w^{*}\right) E\left(\frac{\partial x}{\partial p} \frac{1}{s}\right)\right]+\frac{1}{2} u^{\prime \prime} \frac{d}{d p} \operatorname{var}\left(\pi^{*}\right)=0
$$

Defining $R_{u}$ as before and $\eta^{*} \equiv-E\left(\frac{\partial x}{\partial p} \frac{1}{s}\right)\left(\frac{p^{*}}{E x}\right)$, we can divide (9) by $E\left(\frac{\partial x}{\partial p} \frac{1}{s}\right)$ and $u^{\prime}$ to obtain:

$$
p^{*}\left(1-\frac{1}{\eta^{*}}\right)-w^{*}=\frac{1}{2} R_{\mathrm{u}}\left[\frac{\frac{d}{d p^{*}} \operatorname{var}\left(\pi^{*}\right)}{E\left(\frac{\partial x}{\partial p} \frac{1}{s}\right)}\right]
$$

Notice the similarity with equation (5) for the exporter invoicing in the domestic currency. Again the wedge between marginal revenue and marginal cost hinges on how the variance of profit changes with price set in foreign currency. Since $\operatorname{var}\left(\pi^{*}\right)=\left(\mathrm{p}^{*}-w^{*}\right)^{2} \operatorname{var}(x)$, we find that,

$$
\frac{d}{d p^{*}} \operatorname{var}\left(\pi^{*}\right)=2\left(p^{*}-w^{*}\right) \operatorname{var}(x)+2\left(p^{*}-w^{*}\right)^{2} \operatorname{cov}\left(x, \frac{\partial x}{\partial p} \frac{1}{s}\right)
$$

The first term is positive when $\pi^{*}>0$, but the sign of the second term depends on the nature of the import demand function (a specific form is adopted in the next section). Assume for now that there is no covariance between import demand and marginal revenue. Then substituting (11) into (10) we obtain:

$$
\mathrm{p}^{*}\left(1-\frac{1}{\eta^{*}}\right)-\mathrm{w}^{*}=\mathrm{R}_{\mathrm{u}}\left(\mathrm{p}^{*}-\mathrm{w}^{*}\right) \operatorname{var}(\mathrm{x}) / \mathrm{E}\left(\frac{\partial \mathrm{x}}{\partial \mathrm{p}} \frac{1}{\mathrm{~s}}\right)<0
$$


Thus, the firm will set marginal revenue at less than marginal cost therefore reducing $\mathrm{p}^{*}$ due to variance in exchange rates and demand. The reason is that the variance of profits now depends on the price-cost margin, $\operatorname{var}\left(\pi^{*}\right)=\left(\mathrm{p}^{*}-w^{*}\right)^{2} \operatorname{var}(\mathrm{x})$, which is reduced by lowering price. As will be confirmed using a specific functional form in the next section, an increase in the variance of the exchange rate will lead to a fall in the optimal price $\mathrm{p}^{*}$

\section{Functional Form for Estimation}

The task now is to adopt a specific functional form for demand, which will allow the first order condition for the exporter to be written in a form suitable for estimation. Let the demand function be given by:

$$
x(p, q, I)=\left(\frac{\alpha}{p}-\frac{\beta}{q}\right) I, \alpha, \beta>0,
$$

where $\mathrm{p}=\mathrm{p}^{*} / \mathrm{s}$. This functional form, while not familiar, has very conventional properties:

(a) Decreasing function in own price, $x_{p}<0$;

(b) Increasing in the price of the domestic import-competing good, $x_{q}>0$;

(c) If the price of imported good is sufficiently higher than domestic good, then demand for imported good will be zero, $x>0$ only for $p<q(\alpha / \beta)$.

With pricing in the importing country's currency, we can substitute for $x$ and $\partial x / \partial p$ into (4) or (7) and take logs to obtain:

$$
\ln \frac{\beta}{\alpha}+2 \ln p-\ln q+\ln \left[1-R_{u}(e p x)\left(\sigma_{s}^{2} / e^{2}\right)\right]=\ln \frac{w^{*}}{e}
$$

Equation (14) is simplified by noting that $\ln \left[1-R_{u}(e p x)\left(\sigma_{s}^{2} / e^{2}\right)\right]=-R_{u}(e p x)\left(\sigma_{s}^{2} / e^{2}\right)$. Substituting this expression into equation (14) and rearranging provides a preliminary form for estimation: 


$$
\ln p=\frac{1}{2} \ln \frac{\alpha}{\beta}+\frac{1}{2} \ln q+\frac{1}{2} \ln \left[\frac{w^{*}}{e}\right]+\frac{1}{2} R_{u}(e p x)\left(\sigma_{s}^{2} / e^{2}\right)
$$

Notice that the exchange-rate variance positively affects import prices. The signs of the other coefficients are as expected: higher prices of competing domestically-produced goods $(q)$ cause higher import prices in the domestic currency; while higher expected foreign factor costs $(w * / e)$ also lead to increased import prices.

When the exporter prices in its own currency and the demand function is (13), the first order condition (10) can be written in logs as:

$$
\ln \frac{\beta}{\alpha}+2 \ln p^{*}-\ln (e q)=\ln w^{*}+\ln \left[1-R_{u}\left(\frac{p^{*}-w^{*}}{p^{*} / e}\right) \alpha I \sigma_{s}^{2} / e^{2}\right]
$$

Equation (16) is simplified by defining $\bar{p}=E p \approx p^{*} / e$ and noting that,

$$
\ln \left[1-\mathrm{R}_{\mathrm{u}}\left(\frac{\mathrm{p}^{*}-\mathrm{w}^{*}}{\mathrm{p}^{*} / \mathrm{e}}\right) \alpha \mathrm{I} \sigma_{\mathrm{s}}^{2} / \mathrm{e}^{2}\right]=-\mathrm{R}_{\mathrm{u}}\left(\frac{\mathrm{p}^{*}-\mathrm{w}^{*}}{\mathrm{p}^{*} / \mathrm{e}}\right) \alpha \mathrm{I} \sigma_{\mathrm{s}}^{2} / \mathrm{e}^{2}
$$

As an approximation we then have,

$$
\ln \bar{p}=\frac{1}{2} \ln \frac{\alpha}{\beta}+\frac{1}{2} \ln \frac{w^{*}}{e}+\frac{1}{2} \ln q-\frac{1}{2} R_{u}\left(\frac{p^{*}-w^{*}}{p^{*} / e}\right) \alpha I \sigma_{s}^{2} / e^{2}
$$

Notice the similarity of the estimable form (18) with equation (15). The coefficients on the first three variables have the same expected signs as for an exporter pricing in the domestic currency, while the exchange-rate variance now exerts a negative influence on impor price. This reflects our finding in the last section that an exporting firm pricing in its own currency will lower its price in response to exchange rate variance, while an exporter pricing in the other currency will raise its price. 
Further refinements are needed to obtain a pass-through equation capable of nesting the exponer's choice of pricing in either currency. First, estimation will be carried out with coefficients not necessarily equal to $1 / 2$ as implied by the specific functional form (13). ${ }^{8}$ However, we shall continue to use the condition that the pass-through equation is homogeneous of degree one in $\left(w^{*} / e\right)$ and $q$, meaning that the coefficients of these variables must add up to unity. ${ }^{9}$ Second, we shall treat $\sigma_{s}^{2} / \mathrm{e}^{2}$ as a regressor, and discuss the measurement of this variable below. The terms multiplying this regressor in either (15) or (18) will be treated as constant, though this is not fully justified by an underlying utility function. ${ }^{10}$ Third, we add time subscripts to each of the variables in (15) and (18), including the variance term $\sigma_{\mathrm{s}, \mathrm{l}}^{2} \mathrm{e}_{\mathrm{t}}^{2}$.

In order to measure $\sigma_{\mathrm{s}, \mathrm{l}}^{2} \mathrm{~d} \mathrm{e}_{\mathrm{l}}^{2}$, let $\varepsilon_{\mathrm{l}}$ denote the random forcast error in the log of the spot rate:

$$
\ln s_{t}=E_{\mathfrak{l}-1} \ln s_{\mathfrak{l}}+\varepsilon_{\mathfrak{l}}
$$

Noting that $\varepsilon_{\mathfrak{l}} \approx \ln \left(1+\varepsilon_{l}\right)$ and $E_{l-1} \ln s_{l} \approx \ln e_{l}$, we can write (19) as $\ln s_{\mathfrak{l}} \approx \ln e_{\mathfrak{l}}+\ln \left(1+\varepsilon_{l}\right)$. Taking exponentials yields $s_{\mathfrak{l}} \approx e_{\mathfrak{l}}\left(1+\varepsilon_{\mathfrak{l}}\right)$, from which it follows that,

$$
\sigma_{s, t}^{2} \approx \mathrm{e}_{\mathrm{t}}^{2} \sigma_{\varepsilon, \mathrm{t}}^{2} \text { and so } \sigma_{\varepsilon, \mathrm{t}}^{2}=\left[\sigma_{s, \mathrm{t}}^{2} / \mathrm{e}_{\mathrm{t}}^{2}\right]
$$

\footnotetext{
8 Feenstra (1989, note 10) discusses how to derive demand functions which yield constant coefficients on the terms $\ln \left(w^{*} / e\right)$ and $\operatorname{lnq}$ in $(15)$ and (18), with the coefficients not necessarily equal to $1 / 2$.
}

9 As explained by Feenstra (1989), this property follows directly from the demand function $x(p, q, I)$ being homogeneous of degree zero in prices and income. We shall indirectly test the condition that the coefficients of $\ln \left(w^{*} / e\right)$ and $\ln q$ sum to unity, as discussed below in the context of Purchasing Power Parity.

10 Consider the case where relative risk aversion $R_{r}=R_{u} E \pi$ is constant. Then with invoicing in the importing country's currency, the term $R_{u} e p x=R_{r} / \rho$ multiplies the variance in (15), where $\rho=$ E $\pi /$ epx is expected profits relative to sales revenue - the profit rate. Thus, the coefficient of the variance in (15) would vary when $\rho$ does. With invoicing in the exporter's currency, the term multiplying the variance in (18) can be written as $R_{u}\left(p^{*} \cdot w^{*}\right) e \alpha L / p^{*}=R_{r}[E x+(\beta L / q)] / E x$, making use of (13). If $R_{r}$ is constant and $\beta>0$ is sufficiently small, then this term is nearly constant. 
The pass-through equation (15) or (18) incorporating the above changes appears as:

$$
\ln p_{t}=\alpha_{0}+\alpha_{1}\left(\ln w_{t}^{*}-E_{t-1} \ln s_{t}\right)+\alpha_{2} \ln q_{t}+\alpha_{3} \sigma_{\varepsilon, t^{\prime}}^{2} \quad \alpha_{1}+\alpha_{2}=1
$$

where the sign of $\alpha_{3}$ depends on which currency the exporter prices in. Substituting for the expected exchange rate from (19), we can rewrite this equation as,

$$
\ln p_{t}=\alpha_{0}+\alpha_{1}\left(\ln w_{t}^{*}-\ln s_{l}\right)+\alpha_{2} \ln q_{t}+\alpha_{3} \sigma_{\varepsilon, t}^{2}+\alpha_{1} \varepsilon_{l}, \quad \alpha_{1}+\alpha_{2}=1
$$

Notice that the explanatory variable $s_{l}$ and the error term $\alpha_{1} \varepsilon_{l}$ are contemporaneously correlated from (19), so estimation of (21') by OLS would be inconsistent. Instrumental variables could alleviate this situation but would do so at the expense of less precise coefficient estimates. An altemative, used here, is to recast (21') into Purchasing Power Parity (PPP) form so that the spot exchange rate $\mathrm{s}_{\mathrm{l}}$ is on the left hand side. The PPP form also allows comparison with findings of Frenkel (1981) and Hakkio (1984), as well as other authors who have investigated the relationship between prices and exchange rates. Equation (21') may be rearranged as:

$$
\operatorname{lns} s_{t}=\beta_{0}+\beta_{1}\left(\ln w_{t}^{*}-\ln q_{t}\right)+\beta_{2}\left(\ln q_{t}-\ln p_{t}\right)+\beta_{3} \sigma_{\varepsilon, t}^{2}+\varepsilon_{t}
$$

where:

$$
\beta_{0}=\left(\alpha_{0} / \alpha_{1}\right), \beta_{1}=1, \beta_{2}=\left(1 / \alpha_{1}\right)>1, \beta_{3}=\left(\alpha_{3} / \alpha_{1}\right)
$$

Note that $\left(\ln w_{t}^{*}-\ln q_{\nu}\right.$ appears with a coefficient of $\beta_{1}=1$ in this equation, which is implied by the restriction $\alpha_{1}+\alpha_{2}=1$. The coefficient of unity is interpreted as a Purchasing Power Parity result: an increase in foreign factor prices $w^{*}$ or decrease in domestic import-competing price $q$ will raise the exchange rate $s$ by a like amount. When we estimate (22) in section 6 , we will test whether this coefficient equals one. In the next section we investigate how the possibility of forward covering affects exporters' prices and the estimating equation (22). 


\section{Forward Covering}

Exporting firms which set price in their own currency cannot cover on the foreign exchange market. Revenues are uncertain due to uncertain quantity demanded. The resulting price denominated in the importing country's currency fluctuates with changes in the exchange rate, which in turn causes changes in quantity demanded. Theory still predicts $\alpha_{3}, \beta_{3}<0$ for these exporters even in the presence of forward markets.

The story differs for firms setting price in the domestic (i.e. importing country's) currency because they can cover. Let $f$ denote the price of forward foreign exchange (i.e. exporting country's currency per unit of importing country's currency) at time $t$ - 1 for a contract settled in time $t$. We shall treat $f$ as exogenous, though Hodrick (1989) provides a general equilibrium formulation in which $f$ is endogenous. Then the extent to which firms can cover their foreign revenues depends on how $f$ compares with the expected exchange rate in $e$.

If $f=e$ (that is $t-1 f_{l}=t_{-1} e_{l}$ ) then exporting firms pricing in the importing country's currency would fully cover revenues, since the expected exchange rate in time $t$ is equal to the current price of a forward foreign exchange contract. The profit function would be $\pi^{*}=\left(f p-w^{*}\right) \times(p, q, 1)$, with $\operatorname{var}\left(\pi^{*}\right)=0$. Exchange-rate variance would not affect the firm's profit-maximising decision. Therefore, the variance of the exchange rate would not enter the pricing equation (21), so we obtain $\alpha_{3}=\beta_{3}=0$.

If $f<e$, then the firm faces a tradeoff between expected profit $E\left(\pi^{*}\right)$ and variance of profit $\operatorname{var}\left(\pi^{*}\right)$. There will be some optimal level of forward covering given the firm's risk aversion. Firms reduce expected profit $\left(E \pi^{*}\right)$ by covering but also reduce the variance of profit. Suppose that the firm chooses the fraction $\lambda$ of revenues to cover. Then:

$$
\pi^{*}=\left\{[\lambda f+(1-\lambda) s] p-w^{*}\right\} \times(p, q, 1)
$$

with

$$
\operatorname{var}\left(\pi^{*}\right)=(1-\lambda)^{2} \sigma_{s}^{2}(p x)^{2}
$$


In this case the firm chooses both $\mathrm{p}$ and $\lambda$ to solve:

$$
\max _{p, \lambda} u\left(E \pi^{*}\right)+\frac{1}{2} u^{\prime \prime} v \operatorname{ar}\left(\pi^{*}\right)
$$

Taking the first-order condition with respect to $\lambda$ and rearranging terms results in:

$$
\left[\frac{f-e}{e}\right]=-R_{u} \operatorname{epx}(1-\lambda)\left[\sigma_{s}^{2} / e^{2}\right]
$$

Thus, firms will choose optimally $\lambda<1$ if and only if $f<e .{ }^{11}$ That is, they will choose to cover only a portion of revenues as long as forward foreign exchange contracts yield less of their currency per unit of the other currency than the expected future spot rate. A shorfall in supply of forward contracts could cause this divergence, causing a bidding up the forward price of the exporters' currency and lowering of $f$. We will refer to the right of (24) as the risk premium in the foreign exchange market, and estimate this premium in the next section.

Taking the first-order condition with respect to $p$ results in:

$$
u^{\prime}\left\{[\lambda f+(1-\lambda) e] x+\left[p(\lambda f+(1-\lambda) e)-w^{*}\right] \frac{\partial x}{\partial p}\right\}+\frac{1}{2} u^{\prime \prime} \frac{d}{d p} \operatorname{var}\left(\pi^{*}\right)=0 .
$$

Since,

$$
\frac{d}{d p} \operatorname{var}\left(\pi^{*}\right)=2(p x)(1-\lambda)^{2} \sigma_{s}^{2} p\left(1-\frac{1}{\eta}\right) \frac{\partial x}{\partial p}
$$

we can rewrite the first-order condition as:

$$
p\left(1-\frac{1}{\eta}\right)-\frac{w^{*}}{[\lambda f+(1-\lambda) e]}=(1-\lambda)^{2} \sigma_{s}^{2} R_{u} \frac{p\left(1-\frac{1}{\eta}\right) p x}{[\lambda f+(1-\lambda) e]} .
$$

11 If $\mathrm{f}>\mathrm{e}$ then the exporting firms will optimally choose $\lambda>1$, so they wiil cover more than $100 \%$ of their sales revenues. 
Equation (25) is compared with equation (7) for the firm invoicing in domestic currency. So long as there is an insufficient supply of forward contracts, causing $f<e$ and $\lambda<1$, the firm will price such that marginal revenue exceeds marginal cost, since (25) is positive. A rising variance $\sigma_{s}^{2}$ will lead to a higher gap between marginal revenue and marginal cost, and a higher $p$. On the other hand, the gap between marginal revenue and marginal cost shrinks as $\lambda$ approaches unity. If firms can cover much of their dollar revenues (i.e. as f approaches e), then the variance of the exchange rate does not affect their pricing decision. Thus, when exporters price in the currency of the importing country, the coefficient $\alpha_{3}$ is positive in (21) as is $\beta_{3}$ in (22), although its size depends on the extent of forward covering. The magnitude of $\alpha_{3}$ and $\beta_{3}$ decreases to zero as the portion of covered sales revenue approaches unity.

Estimation of (22) will be estimated at an aggregate level by country. Thus, it will combine the response of firms invoicing in both currencies. But the choice of invoicing currency affects the sign and significance of the variance term. Consider first the case when $f$ approximately equals $e$. Variance will have no effect on exporters setting price in the importing country's currency since they will cover revenues. In such a case $\beta_{3}$ is predicted to be negative, reflecting the remaining effect of variance on exporters pricing in their own currency as discussed above. Now consider the case where $f$ is less than $e$. The sign on exchange rate variance will be negative for exporters pricing in their own currency as before. But now exporters pricing in the importing country's currency will not be fully covering, causing $\beta_{3}$ to also have a positive sign. In this latter case one cannot predict a sign for $\beta_{3}$ when estimated at the aggregate level. In fact, it is likely to be statistically insignificant when tested empirically. Summing up, if the estimated risk premium in (24) is negative and significant, we can expect an ambiguous sign on the exchange rate variance in (22); while if the risk premium in (24) is insignificant so that full forward covering occurs, then we expect the exchange rate variance should have a negative coefficient in (22). These results will be tested in section 6 , after first obtaining estimates of the exchange rate variance. 


\section{Estimation of the ARCH-M Model}

Our task in this section is to estimate (24), thereby obtaining a measure of the risk premium and exchange rate variance. To put this equation in an estimable form, approximate the left side by the difference between the logs of the forward and expected exchange rate, and make use of (19) and (20). Then adding the appropriate time subscripts, we can rewrite (24) as,

$$
\begin{aligned}
& \text { l-1 } \operatorname{lnf} f_{l}-\ln s_{l}=\gamma_{0}+\delta h_{l}+\varepsilon_{l}, \\
& \xi \mid I_{l-1} \sim N\left(0, h_{t}\right), \\
& h_{t}=\phi_{0}+\phi_{1} \varepsilon_{t-1}^{2}+\phi_{2} h_{t-1} \text {, }
\end{aligned}
$$

where $h_{t}$ replaces $\sigma_{s, t}^{2} / e_{t}^{2}$ in (24) and is the conditional variance of the forecast error $\varepsilon_{t}$, while the coefficient $\delta$ replaces $-R_{u} \operatorname{epx}(1-\lambda)$ from (24). Note that $\lambda<1$ implies $\delta<0$, in which case full forward covering does not occur. The resulting equation (26) is an ARCH-in-Mean process, as proposed by Engle, Lilien, and Robins (1987), in which conditional variance becomes an explanatory variable of the mean equation. Domowitz and Hakkio (1985) have used ARCH-M to test their empirical model of exchange-rate risk premia, where the risk premium was a function of the conditional variance of market forecast errors, as in our specification. The inclusion of $\phi_{2} h_{1-1}$ in (26c) is a generalisation of ARCH (sometimes called GARCH) due to Bollerslev (1986), and this technique combined with ARCH-M has been standard practice in recent literature as in Engle and Bollerslev (1986) and also Kaminsky and Peruga (1990).

Estimation of equation (26) is carried out using spot and one-month forward exchange-rate data for days $7,14,21$, and 28 of each month. Currencies chosen were the pound, yen and mark price of the U.S. dollar. Our data covers the period June 1974 to September 1988 - a total of 688 observations; the Appendix covers more thoroughly the sources and description of the data. Use of weekly data increases the number of observations, but this also adds moving average terms to the error, up to four successive observations will be influenced by the same shocks since the 
observation interval is finer than the relevant forward-contract interval [as pointed out by Hansen and Hodrick (1980)]. Incorporating these moving average error terms, the ARCH-M model is rewritten as:

$$
1.4 \ln f_{t}-\ln s_{t}=\gamma_{0}+\delta h_{t}+\gamma_{1} \varepsilon_{-1}+\gamma_{2} \varepsilon_{-2}+\gamma_{3} \varepsilon_{-3}+\gamma_{4} \varepsilon_{-4}+\varepsilon_{t}
$$

while (26b) and (26c) appear as before,

Maximum likelihood estimates of the ARCH-M models for the three countries are found by making use of the Berndt, Hall, Hall, Hausman (1974) algorithm. ${ }^{12}$ The results are shown in Table 1. The ARCH-M coefficients $\phi_{1}$ and $\phi_{2}$ are highly significant for all three currencies indicating the presence of time-varying heteroskedasticity in the error terms. Note that $\phi_{1}$ is a sizable magnitude for all currencies. Thus, a large squared forecast error in one period tends to be followed by a large forecast error in the next period. The size of the $\phi_{2}$ term is even larger, indicating the lingering but declining importance of all past information.

Figures 1 through 3 graph the conditional variance estimates. Common to both the yen and the pound is a large blip of increased variance in the latter part of the sample period. However, the pound experiences this oddity around August 1985 while the yen follows the same pattern in January 1986. The mark shows relatively little variability after a brief period in February 1979.

The ARCH-M term $\delta$ is significant and negative only for the yen. Interpreted on the basis of theory derived in the last section, the results suggest that risk-averse exporting firms in Japan are not covering fully in the foreign exchange market. In Figure 4 we show the risk premium for the yen, that is, the estimated value of the right of (26a). Notice that except for the first four years of the sample and a period around 1984, the estimated risk premium is negative, indicating that the yen had a higher value in forward markets than its expected future spot price. This premium is most dramatic in 1985 , when the yen appreciated substantially against the dollar.

12 The FORTRAN program used for estimation was graciously supplied by Ken Kroner, Department of Economics, University of Arizona. 
The pound and mark estimations yield insignificant variance estimates in the mean equations. These two currencies are widely traded (being an integral part of the European Economic Common Market) so one would expect the forward exchange rate to more nearly equal the expected future spot rate. The above results, particularly the exchange rate variance estimates, are now utilized in estimating the pass-through equation in its PPP form.

\section{Pass-Through Estimation}

In estimating the pass-through relation (22), the United States will be the 'domestic' country while three major industrialised countries - United Kingdom (UK), Japan, and the Federal Republic of Germany - comprise the 'foreign' countries. Exports from these countries to the United States are mostly heterogeneous manufactured goods. The pass-through equation derived in section 2 specifically addresses these types of goods as it is premised on price-setting behaviour by exporters. Aggregate quarterly data (see the Appendix for details) from 1974:3 to 1988:1 comprise the sample period.

Variables of equation (22) for the three countries are as follows. The dependent variable (lns) is the average quarterly spot rate of foreign currency per US dollar. Period averages seem more reasonable than using end-of-quarter figures since exporters ship goods throughout the period. Foreign marginal costs ( $\left.\ln w^{*}\right)$ are wholesale price indices of the respective foreign countries, as is the US domestic price (lnq $\mathcal{V}^{13}$ The US import price variable (lnp ${ }_{\mathcal{V}}$ ) is a Divisia index which excludes the following categories of imports: (1) Food, feeds, and beverages; (2) Petroleum products; and (3) Automobiles. These sectors were omitted because they did not conform to the imperfectly competitive model of section 2 (as with food), due to cartel behavior (as with oil), or due to import quotas (as with autos). As a rough approximation, one finds that the combined importance of the excluded goods account for an average $45 \%$ of total US imports,

13 Other indexes were tried such as the GDP deflator, consumer price index and unit labour value. Results with these indices were less precise than with the wholesale price index. 
leaving 55\% to be explained by the model. The last variable of equation (22) is the estimate of exchange rate variance which is obtained from section $5.1^{14}$

Note that there is one respect in which our data do not closely correspond to the theoretical model of sections $2-4$, and that is in the use of the U.S. aggregate import price index - which includes imports from all countries - for $\ln p$. It would be more appropriate to use a bilateral price index for imports from each of the U.K., Japan and Germany to the U.S., but such price indexes are not available. Thus, our measure of $\operatorname{lnp}_{\mathfrak{l}}$ in equation (22) is somewhat inadequate, especially since the dependent variable is the bilateral exchange rate. We will judge by the results whether this limitation of the data is serious.

\subsection{Dynamic Specification}

Theory seldom provides a precise dynamic specification for estimation; equation (22) in its static form is no exception. A search for the correct dynamic specification begins with an "unrestricted" model that nests alternative "restricted" models. The restricted models are then subjected to quasi-likelihood ratio tests. The most parsimonious representation that adequately models the process is selected on the basis of these tests. An autoregressive-distributed $(\operatorname{AD}(1,1))$ model as defined by Hendry (1980) describes the unrestricted specification in levels:

$$
\begin{aligned}
\ln s_{t}= & \beta_{0}+\beta_{1}\left(\ln w_{t}^{*}-\ln q_{t}+\beta_{2}\left(\ln w_{t-1}^{*}-\ln q_{t-1}\right)+\beta_{3}\left(\ln q_{t}-\ln p_{t}\right)+\right. \\
& \beta_{4}\left(\ln q_{t-q}-\ln p_{t-1}\right)+\beta_{5} \ln s_{t-1}+\beta_{6} \sigma_{\varepsilon, t}^{2}+\beta_{7} \sigma_{\varepsilon, t-1}^{2}+v_{t}
\end{aligned}
$$

An obvious dynamic specification to test is the Cochrane-Orcutt correction for first-order serial correlation, i.e. where the error term $\varepsilon_{\text {f }}$ from the static model follows,

$$
\varepsilon_{t}=\rho \varepsilon_{t-1}+v_{t}
$$

14 The exchange rates variances are averaged to quarterly frequency for use in the PPP equation. 
and $v_{t}$ is white noise. Both Hendry (1980) and Hoover (1988) show how one can restrict equation (27) to obtain an equivalent Cochrane-Orcutt correction. Imposing the common factor restrictions, $\beta_{2}=-\beta_{1} \beta_{5}, \beta_{4}=-\beta_{3} \beta_{5}$, and $\beta_{7}=-\beta_{6} \beta_{5}$ results in:

$$
\begin{aligned}
\ln s_{t} & =\beta_{0}+\beta_{1}\left(\ln w_{t}^{*}-\ln q_{\nu}\right)-\beta_{1} \beta_{5}\left(\ln w_{t}^{*}-\ln p_{t-1}\right)+\beta_{3}\left(\ln q_{t}-\ln p_{L}\right. \\
& -\beta_{3} \beta_{5}\left(\ln q_{t}-\ln p_{t-1}\right)+\beta_{5} \ln s_{t-1}+\beta_{6} \sigma_{\varepsilon, t}^{2}-\beta_{6} \beta_{5} \sigma_{\varepsilon, t-1}^{2}+v_{t}
\end{aligned}
$$

where $\beta_{5}$ is the extent of first-order autocorrelation $\rho$.

Equation (27) was estimated using instrumental variables (IV) for Great Britain, Japan, and Germany .15 Quasi-likelihood ratio (QLR) tests were computed using the relevant country's unrestricted model as maintained hypothesis. ${ }^{16}$ Both Great Britain and Germany yield chi-squared statistics (with three degrees of freedom) of 13.9 and 18.5 respectively. Clearly these values indicate rejection of the Cochrane-Orcutt specification at the ten per cent level of significance. Japan, on the other hand, yields a chi-squared statistic of 4.0 which fails to reject the restriction even at the twenty per cent significance level.

The unfavourable results for Great Britain and Germany indicate that further exploration of the dynamic process behind equation (27) is needed. Hendry et al (1984, p.1070) suggest specifying the unrestricted model in an equivalent difference-level form which would nest an error correction mechanism (ECM) as well as a simple difference specification. Advantages of this type

15 IV are needed since if producers can have knowledge of exchange rates within a quarter, and use this to adjust prices on the right of (27). The instruments used were the current and lagged variance and lagged endogenous variables from each equation, together with current and lagged values of money ( $\mathrm{ml}$ ) and real GDP (or GNP) for each of the countries and the US. Finally time and time-squared are included since the levels of the price variables are heavily trended.

16 The test statistic used was $n(Q D 0-Q D 1) / s^{2}$ where $Q D 0$ is the value of the minimum distance criterion (sum of squared residuals after regressors are fitted on the instrument) for the null hypothesis; QD1 is its value for the alternative hypothesis (i.e. the "unrestricted" regression); $s^{2}$ is the standard error, squared of the unrestricted regression; and $\mathrm{n}$ is the number of observations. See Gallant and Jorgenson (1979). 
of specification include retaining long-run information but circumventing "the most basic 'spurious' regressions problem" [Hendry (1984, p.1070)]. Indeed raw exchange rate data are well-known to be nonstationary (i.e. have unit roots) as noted in Meese and Singleton (1982). Equation (27) respecified would appear as:

$$
\begin{aligned}
\Delta \ln s_{t}= & \beta_{1} \Delta\left(\ln w_{t}^{*}-\ln q_{t}\right)+\beta_{2}\left(\ln w_{t-1}^{*}-\ln q_{t-1}\right)+\beta_{3} \Delta\left(\ln q_{t}-\ln p_{t}\right)+ \\
& \beta_{4}\left(\ln q_{t-1}-\ln p_{t-1}\right)+\beta_{5} \ln s_{t-1}+\beta_{6} \sigma_{\varepsilon, t}^{2}+\beta_{7} \sigma_{\varepsilon l-1}^{2}+v_{t} .
\end{aligned}
$$

An ECM specification is easily nested within the above model by setting $\beta_{2}=-\beta_{5}$ and $\beta_{7}=0$ :

$$
\begin{aligned}
& \Delta \operatorname{lns} s_{l}=\beta_{1} \Delta\left(\ln w_{l}^{*}-\ln q_{1}\right)+\beta_{2}\left[\left(\ln w_{l-1}^{*}-\ln q_{l-1}\right)-\ln s_{l-1}\right]+ \\
& \beta_{3} \Delta\left(\ln q_{t}-\ln p_{t}\right)+\beta_{4}\left(\ln q_{t-1}-\ln p_{t-1}\right)+\beta_{6} \sigma_{\varepsilon, t}^{2}+v_{t} .
\end{aligned}
$$

An advantage of the ECM is that it allows short-run adjustment of regressors to their respective steady-state values. Pass-through theory in section 2 implies long-run cointegration between the spot exchange rate $\left(\mathrm{lns}_{\mathrm{l}}\right)$ and the foreign marginal costs relative to US domestic prices $\left(\ln w_{t-1}^{*}-\ln q_{t-1}\right)$; in other words, that PPP holds in the long run. However, the theory imparts no information about short-run deviation from this relationships. It is in the short run then that the ECM 'measures the 'error' in the previous period and agents 'correct' their decision about $\left(s_{t}\right)$ in light of this initial disequilibrium" [Hendry (1980)].

Equation (30) can be re-expressed to highlight the feedback effect of the EC terms on the exchange rate:

$$
\begin{aligned}
& \Delta \operatorname{lns} s_{l}=\beta_{1} \Delta\left(\ln w_{l}^{*}-\ln q_{l}\right)+\beta_{3} \Delta\left(\ln q_{l}-\ln p_{\mathcal{U}}\right)+\beta_{6} \Delta \sigma_{\varepsilon, \mathrm{l}}^{2}+ \\
& \beta_{2}\left[-\ln s_{t-1}+\left(\ln w_{t-1}^{*}-\ln q_{t-1}\right)+\left(\frac{\beta_{4}}{\beta_{2}}\right)\left(\ln q_{t-1}-\ln p_{t-1}\right)+\left(\frac{\beta_{6}}{\beta_{2}}\right) \sigma_{\varepsilon, t-1}^{2}\right]+v_{t} \text {. }
\end{aligned}
$$


The final bracketed term of equation (30') groups together components of the errorcorrection mechanism. To gain some intutition about this term, suppose that foreign factor prices increase faster than domestic prices causing (lnwl- $w_{l}^{*} q_{1}$ to increase. The responsiveness of the spot exchange rate to a change in this argument is $\beta_{1}$, its short-run elasticity. But now suppose that after one period $\left(\ln w_{i}^{*}-\ln q_{\nu}\right.$ stays at its new level. Then $\Delta\left(\ln w_{i}^{*}-\ln q_{i}\right)=0$. Nevertheless, the exchange rate will continue to change due to feedback from the error-correction term. In fact the EC term equals zero if and only if the exchange rate is at its long-run level. When the exchange rate is above (below) its long-run level, the $\mathrm{EC}$ term will be negative (positive), lowering (raising) the exchange rate in the next period (for $\beta_{2}>0$ ).

The long-run level of the exchange rate implied by (20) is found by setting all changes in variables equal to zero, and combining current and lagged variables. This results in:

$$
\ln s_{l}=\left(\ln w_{l}^{*}-\ln p_{j}+\frac{\beta_{4}}{\beta_{2}}\left(\ln q_{l}-\ln p_{j}\right)+\frac{\beta_{6}}{\beta_{2}} \sigma_{\varepsilon, t}^{2} .\right.
$$

Notice the similarity between equation (31) and equation (22). The ECM preserves the static relationship in the long run (when variables have attained their equilibrium values) while simultaneously affording a flexible lag structure in the short run. The coefficient of unity on the variable $\left(\ln w_{1}^{*}-\ln p 0\right.$ is interpreted as a PPP result. Estimates from equation (31) can be readily inverted in order to obtain the pass-through relationship of equation (21').

Nested within the ECM is a difference model. If $\beta_{2}=\beta_{4}=0$ in (30) then only relationships between differenced variables hold, appearing as:

$$
\Delta \ln s_{l}=\beta_{1} \Delta\left(\ln w_{l}^{*}-\ln q_{\mathcal{U}}+\beta_{3} \Delta\left(\ln q_{l}-\ln p_{U}\right)+\beta_{6} \sigma_{\varepsilon, l}^{2}+v_{l}\right.
$$

Here changes in $\left(\ln w_{l}^{*}-\ln q_{\nu}\right.$ or $\left(\ln q_{l}-\ln p_{0}\right)$ affect the exchange rate immediately, with no errorcorrection feedback. However, movements in exchange rate variance now affect the change in the 
exchange rate rather than its level, because this variable is not differenced. ${ }^{17}$

Selection of the appropriate dynamic specification for each country proceeds as follows: the unrestricted model is estimated for each of the countries by instrumental variables. Then the restricted models above are estimated (i.e. nested in the unrestricted model but successively more restrictive). Quasi-likelihood ratio (QLR) tests are used to chose among the different specifications for each country.

\subsection{Estimation Results and Hypothesis Testing}

Results of the instrumental variables estimation are presented in Table 2. The unrestricted estimation exhibits short-run PPP coefficients $\left(\beta_{1}\right)$ ranging from 1.04 (insignificant) for the UK to 2.62 and 2.52 for Japan and Germany respectively (both significantly greater than one at the $95 \%$ level). ${ }^{18}$ In general one would expect to find a wide variety of coefficient magnitudes in this model; it is bound to exhibit a high degree of multicollinearity in the effort to nest competing dynamic specifications.

It is plausible (though not theoretically necessary) to expect the elasticity of export prices with respect to marginal costs $w^{*} / \mathrm{s}$ to be less than unity in the model of section 2 , meaning that $\alpha_{1}<1.19$ When recast in PPP form this implies a coefficient greater than one for the $\Delta\left(\operatorname{lnq}_{1}-\ln p_{v}\right)$ regressor: the $\beta_{3}$ estimates for each of the countries satisfies this. Interestingly, the estimates of $\beta_{6}$ (the variance coefficient) across the three countries are all negative and within the same order of magnitude, although not significant for Japan.

17 We experimented with differencing the exchange rate variance, but found little change in the estimates, though there was some decline in efficiency (this alternative specification was estimated for the UK, in particular).

18 Our standard errors should be interpreted with caution, since we are treating the exchange rate variances as data rather than estimated variables. As noted in Hodrick (1989), this procedure gives standard errors that are less than their consistent values.

19 Feenstra (1989) discusses how this elasticity can exceed unity, depending on properties of the demand function $x(p, q, I)$. 
Quasi-likelihood ratio values are presented in Table 3 for the restricted models (30) and (32). All countries fail to reject the ECM specification for a chi-squared statistic with two degrees of freedom at the $10 \%$ level. On the other hand, only the UK and Japan fail to reject the difference specification at an acceptable level of significance. As a further refinement, the PPP coefficients $\left(\beta_{1}\right)$ for the countries are restricted to equal one. The resulting chi-squared statistics show acceptance for both the UK and Japan but obviously not for Germany. Thus, the UK seems adequately modelled by differences while Germany is characterised better by the ECM. Japan appears amenable to either the ECM or differences specifications. The ECM, however, yields more plausible parameter estimates for Japan. Table 2 also presents the instrumental variables estimates of the preferred restricted model for each country.

Together, the above models are estimated simultaneously by three-stage least squares (3SLS). Estimation in this fashion allows incorporation of cross-country correlation. Hakkio (1984) has noted its imponance in his multi-currency estimation of Purchasing Power Parity. Table 4 shows the 3SLS estimation for the three countries, and can be directly compared with the IV estimates of Table 2. Noticeable are the changes in the parameter estimates as well as the sign reversal on the lagged variance term $\beta_{7}$ for Germany. Noticeable too are the reductions in standard errors; taking account of cross-country correlation has a pronounced effect on the efficiency of the parameter estimates. The variance coefficients of the restricted models do appear to be significant and uniform in size across countries although small in magnitude. Thus, exchange rate volatility is associated with a depreciation of the foreign currencies relative to the US dollar.

Further inferences can be made from the long-run equation (31) presented in Table 5, which is computed from the 3SLS estimates in Table 4. ${ }^{20}$ These estimates apply when the exchange rate has reached its equilibrium value. For the UK we use the difference model (32) as the long-run

20 The estimates and accompanying standard errors are computed using the "ANALYZ" command in TSP version 4.1. Implied coefficient variances are linearly approximated combinations of estimated variances and covariances. 
relationship. The coefficient estimate on (lnqt - $\ln \mathrm{l}_{\mathrm{J}}$ exceeds unity for the UK and Japan but is perversely less than one for Germany. This result may be due to our inadequate measure of the traded goods prices $\operatorname{lnp}_{t}$ (reflecting all U.S. imports rather than bilateral trade), which could lead to an underestimate of the coefficient on $\left(\ln q_{t}-\ln p_{t}\right)$. The result for Germany is perverse because it implies that an increase in domestic prices negatively affects US import prices in the pass-through equation, shown in the lower part of Table 5, which are obtained by inverting the PPP equations. Note also that in the German pass-through equation, the coefficient on (Inw* - Inpt) exceeds unity, meaning that an appreciation of the exporter's currency is more than fully passed-through to expor prices. This surprisingly result is again due to the low coefficient on $\left(\operatorname{lnq}_{l}-\ln p \nu\right.$ in the German PPP equation, but interestingly, Mann (1989) also finds such a result to hold for several highly disaggregated export products from Germany. ${ }^{21}$

The variance coefficients in the PPP or pass-through equations differ in magnitude for the three countries, although all are negative. It is noticeable that the estimate for Japan is insignificant. The theory developed in section 2 implies that if exporters are able to fully cover their US dollar revenues, then the variance can only negatively affect the US dollar price for their goods (this effect comes from exporters pricing in their own currency). As noted in section 5 , the variance coefficient in the mean equation for the UK and Germany was insignificant, implying the ability of agents to cover completely: hence, results for the UK and Germany in Table 5 are consistent with our theory. For Japan, there was significant evidence of a risk premium in the ARCH-M equation, leading to less than complete covering, so we would predict an ambiguous effect of the exchange rate variance on the exchange rate or export prices. This prediction is also supported by our results in Table 5, where the variance coefficient for Japan is insignificant.

21 In particular, she finds that with an appreciation of the mark, German producers of several products would raise their mark-denominated prices. She speculates (p. 612) that her data could represent destination-market prices (e.g. dollar denominated) rather than the home currency prices. Recall that in theory, pass-through of greater than unity is possible (see footnote 19). 


\section{Conclusions}

In this paper we have analysed partial equilibrium models which highlight the differing effects of exchange rate variance on risk-averse profit maximising exporting firms, with the possibility of forward covering. Invoicing in the importing country's currency led to a positive relationship between exchange-rate variance and import prices, while invoicing in the exporter's own currency had the opposite effect. If risk-averse exporters could fully cover revenues, then they would not be affected by exchange rate variance. However, they would not cover fully if the forward price of foreign exchange was less than the expected future spot rate, since then some tradeoff between higher expected profit and risk is optimal.

Exchange rate variance was estimated as a generalized ARCH-M model. Estimation based on weekly data (1974 to 1988) revealed a significant and negative coefficient for exchange rate variance as well as a predominantly negative risk premium for Japan (i.e. forward rate less than expected future spot rate). On the other hand, the UK and Germany exhibited insignificant coefficients on exchange rate variance. Notably all currencies exhibited strong evidence of ARCH effects; the exchange rate variances which were obtained from the $\mathrm{ARCH}$ model were used in subsequent estimation of the pass-through relation.

The pass-through equation was reworked into a dynamic form of PPP, with the exchange rate as the dependent variable. After testing various specifications of the dynamic model, the data supported an error-corection mechanism for Japan and Germany, and a simple difference form for the UK. These were estimated with IV and 3SLS methods. Our results, particularly the long-run equations in Table 5, are quite supportive of the underlying theory. Japan was the only country with a significant risk premium in the foreign exchange market, and consistent with this, the exchange rate variance had an ambiguous (insignificant) effect on export prices: due to inadequate forward covering, firms pricing in dollars will raise their prices in response to variance, while firms pricing in yen will lower their prices. For the UK and Germany there was no risk premium so that firms pricing in dollars could cover to eliminate risk: the only remaining effect is for exponters pricing in their own currencies to lower prices in reponse to exchange rate variance. 
Thus, for these two countries we found a negative and significant effect of the exchange rate variance on export prices.

The objective of this paper was to determine how volatility of the exchange rate affects the pricing decision of exporting firms. Ultimately, our interest in this topic may revolve around the question of how exchange rate variance (reflecting the stochastic nature of underlying monetary and fiscal policies) may affect the equilibrium level of the exchange rate. We have not addressed this question here, though our model can be used as a building block towards this end. In particular, our modified-PPP equation (22) could be integrated into a monetary model of exchange rate determination, such as presented by Woo (1985) and West (1987). Indeed, West (1987) emphasizes that stochastic deviations from PPP (and shocks to money demand) play a crucial role in his failure to reject the monetary model, and states that "It is therefore of interest in future work to model these shocks as functions at least in part of observable economic variables" (p. 72). Our modified-PPP equation is a first step along these lines. It is also noteworthy that Hodrick (1989), who specifies a theoretical model of exchange rate determination which includes the variance of money supply and GNP, does not find evidence that these variance terms are related to exchange rate levels. The firm-based model of export pricing developed here is quite different from the theoretical analysis of Hodrick, so it is possible that the resulting equations of exchange rate determination could lead to empirical results where the variance of monetary and fiscal policies are important. 
TABLE 1: ARCH-IN-MEAN ESTIMATES

$$
\begin{gathered}
\mathrm{t}-4 \ln f_{\mathrm{t}}-\ln s_{\mathrm{l}}=\gamma_{0}+\delta \mathrm{h}_{\mathrm{l}}+\gamma_{1} \varepsilon_{\mathrm{l}-1}+\gamma_{2} \varepsilon_{\mathrm{l}-2}+\gamma_{3} \varepsilon_{\mathrm{l}-3}+\gamma_{4} \varepsilon_{\mathrm{l}-4} \\
\mathrm{~h}_{\mathrm{l}}=\phi_{0}+\phi_{1} \varepsilon_{\mathrm{t}-1}^{2}+\phi_{2} \mathrm{~h}_{\mathrm{t}-1}, \quad \varepsilon_{\mathrm{l}} \mid \mathrm{I}_{\mathrm{t}-1}-N\left(0, \mathrm{~h}_{\mathrm{l}}\right)
\end{gathered}
$$

POUND

0.296

$(0.30)$

$-0.0853$

$(0.085)$

0.964

$(0.043)$

0.977

(0.041)

$\gamma_{3}$

$\gamma_{4}$

$\phi_{0}$

$\phi_{1}$

$\phi_{2}$

0.0754

$(0.040)$

0.100

$(0.032)$

0.118

$(0.025)$

0.855

(0.027)
$-1272.768$
1.633
2.927

Log Likelihood

Mean of $h^{.5}$

Mean of $h$

YEN

0.509

$(0.31)$

$-0.244$

(0.092)

1.011

(0.042)

1.003

(0.047)

0.851

$(0.050)$

0.110

(0.044)

0.0619

(0.018)

0.101

(0.015)

0.885

(0.017)

-1274.431
1.662
3.132

MARK

0.0902

(0.25)

0.0084

(0.059)

0.982

(0.048)

0.952

(0.045)

0.855

(0.046)

0.0955

(0.042)

0.186

(0.062)

0.164

(0.029)

0.786

(0.040)

$$
\begin{gathered}
-1306.822 \\
1.714 \\
3.267
\end{gathered}
$$

Number of Observations $=687$. Standard errors are in parentheses. 
TABLE 2: IV ESTIMATES

\begin{tabular}{|c|c|c|c|c|c|c|}
\hline \multirow[b]{3}{*}{$\beta_{1}$} & \multicolumn{5}{|c|}{$\beta_{5} \ln s_{t-1}+\beta_{6} \sigma_{\varepsilon, t}^{2}+\beta_{7} \sigma_{\varepsilon, t-1}^{2}$} & \\
\hline & \multirow{2}{*}{$\begin{array}{l}\text { UNITED } \\
1.041 \\
(0.935)\end{array}$} & \multirow{2}{*}{$\begin{array}{c}\text { KINGDOM } \\
1 \\
\text { (restricted) }\end{array}$} & \multicolumn{2}{|c|}{ JAPAN } & \multicolumn{2}{|c|}{ GERMANY } \\
\hline & & & $\begin{array}{l}2.62^{*} \\
(0.861)\end{array}$ & $\begin{array}{c}1.757^{*} \\
(0.520)\end{array}$ & $\begin{array}{r}2.521^{*} \\
(0.813)\end{array}$ & $\begin{array}{l}2.810^{*} \\
(0.824)\end{array}$ \\
\hline$\beta_{2}$ & $\begin{array}{c}0.038 \\
(0.129)\end{array}$ & & $\begin{array}{c}0.458 \\
(0.368)\end{array}$ & $\begin{array}{r}0.0361 \\
(0.036)\end{array}$ & $\begin{array}{c}0.0393 \\
(0.0838)\end{array}$ & $\begin{array}{c}0.164^{*} \\
(0.057)\end{array}$ \\
\hline$\beta_{3}$ & $\begin{array}{r}2.275^{*} \\
(0.833)\end{array}$ & $\begin{array}{l}2.171^{*} \\
(0.599)\end{array}$ & $\begin{array}{c}2.33^{*} \\
(1.07)\end{array}$ & $\begin{array}{c}1.335^{*} \\
(0.625)\end{array}$ & $\begin{array}{r}2.300^{*} \\
(0.478)\end{array}$ & $\begin{array}{c}2.398^{*} \\
(0.489)\end{array}$ \\
\hline$\beta_{4}$ & $\begin{array}{l}-0.00075 \\
(0.0162)\end{array}$ & & $\begin{array}{c}0.324 \\
(0.251)\end{array}$ & $\begin{array}{c}0.0576 \\
(0.0561)\end{array}$ & $\begin{array}{l}0.0411^{*} \\
(0.0125)\end{array}$ & $\begin{array}{c}0.0373^{*} \\
(0.0126)\end{array}$ \\
\hline$\beta_{5}$ & $\begin{array}{l}-0.0120 \\
(0.0697)\end{array}$ & & $\begin{array}{l}-0.209 \\
(0.163)\end{array}$ & $\begin{array}{l}-0.0361^{* * *} \\
(-0.036)\end{array}$ & $\begin{array}{l}-0.164^{*} \\
(0.055)\end{array}$ & $\begin{array}{l}-0.164^{* * *} \\
(-0.057)\end{array}$ \\
\hline$\beta_{6}$ & $\begin{array}{l}-0.0091 * * \\
(0.0048)\end{array}$ & $\begin{array}{l}-0.0060^{*} \\
(0.0019)\end{array}$ & $\begin{array}{l}-0.0046 \\
(0.0038)\end{array}$ & $\begin{array}{l}-0.0045 \\
(0.0027)\end{array}$ & $\begin{array}{l}-0.0063^{*} \\
(0.0022)\end{array}$ & $\begin{array}{l}-0.0052^{*} \\
(0.0022)\end{array}$ \\
\hline$\beta_{7}$ & $\begin{array}{c}0.0015 \\
(0.0047)\end{array}$ & & $\begin{array}{c}0.0036 \\
(0.0032)\end{array}$ & & $\begin{array}{l}0.000015 \\
(0.00224)\end{array}$ & \\
\hline Distance & 0.0406 & 0.0426 & 0.0343 & 0.0397 & 0.0161 & 0.0214 \\
\hline$S S R^{b}$ & 0.113 & 0.114 & 0.0767 & 0.0758 & 0.0589 & 0.0654 \\
\hline $\mathrm{R}^{2}$ & 0.278 & 0.272 & 0.500 & 0.491 & 0.561 & 0.514 \\
\hline DWc & 1.671 & 1.793 & 2.195 & 2.060 & 1.951 & 1.897 \\
\hline
\end{tabular}

\section{Notes}

Sample is 1975:1 TO 1988:1 (53 observations). Standard errors are in parentheses.

* Significant at the $95 \%$ level.

** Significant at the $90 \%$ level.

*** Restricted to equal $-\beta_{2}$.
a Minimum distance criterion (SSR after regressors are fitted on instruments).
b Sum of squared residuals.
c Durbin Watson statistic. 
TABLE 3

QUASI-LIKELIHOOD RATIO TESTS ON RESTRICTED MODELS

(Null hypothesis)

UNRESTRICTED MODEL

(Alternative hypothesis)

1. RESTRICTED MODEL: ERROR CORRECTION

UNITED KINGDOM

$0.78<\chi_{.10}^{2}(2)=4.61$

JAPAN

$3.28<\chi_{.10}^{2}(2)=4.61$

GERMANY

$4.17<\chi_{.10}^{2}(2)=4.61$

2. RESTRICTED MODEL: DIFFERENCES

UNITED KINGDOM

JAPAN

GERMANY

3. RESTRICTED MODEL:

DIFFERENCES: $\beta_{1}=1$

UNITED KINGDOM

JAPAN

$0.78<\chi_{.10}^{2}(4)=7.78$

$4.44<\chi_{.10}^{2}(4)=7.78$

$13.56>\chi_{.10}^{2}(4)=7.78$

GERMANY

$0.80<\chi_{.10}^{2}(5)=9.24$

$5.81<\chi_{.10}^{2}(5)=9.24$

$13.68>\chi_{.10}^{2}(5)=9.24$ 
TABLE 4: 3SLS ESTIMATES

\begin{tabular}{|c|c|c|c|c|c|c|}
\hline \multirow[b]{3}{*}{$\beta_{1}$} & \multicolumn{5}{|c|}{$\beta_{5} \ln s_{l-1}+\beta_{6} \sigma_{E, t}^{2}+\beta_{7} \sigma_{E, t-1}^{2}$} & \\
\hline & \multirow{2}{*}{$\begin{array}{c}\text { UNITED } \\
1.662^{*} \\
(0.671)\end{array}$} & \multirow{2}{*}{$\begin{array}{c}\text { KINGDOM } \\
1 \\
\text { (restricted) }\end{array}$} & \multicolumn{2}{|c|}{ JAPAN } & \multicolumn{2}{|c|}{ GERMANY } \\
\hline & & & $\begin{array}{l}1.931^{*} \\
(0.403)\end{array}$ & $\begin{array}{r}1.719 * \\
(0.321)\end{array}$ & $\begin{array}{r}1.434^{*} \\
(0.544)\end{array}$ & $\begin{array}{c}1.589^{*} \\
(0.540)\end{array}$ \\
\hline$\beta_{2}$ & $\begin{array}{c}0.108 \\
(0.099)\end{array}$ & & $\begin{array}{c}0.153 \\
(0.195)\end{array}$ & $\begin{array}{c}0.0211 \\
(0.0256)\end{array}$ & $\begin{array}{c}0.0220 \\
(0.0660)\end{array}$ & $\begin{array}{l}0.0912^{*} \\
(0.0371)\end{array}$ \\
\hline$\beta_{3}$ & $\begin{array}{r}2.289^{*} \\
(0.626)\end{array}$ & $\begin{array}{r}1.881^{*} \\
(0.487)\end{array}$ & $\begin{array}{l}1.389^{*} \\
(0.536)\end{array}$ & $\begin{array}{l}1.081^{*} \\
(0.438)\end{array}$ & $\begin{array}{r}2.221^{*} \\
(0.379)\end{array}$ & $\begin{array}{l}2.315^{*} \\
(0.374)\end{array}$ \\
\hline$\beta_{4}$ & $\begin{array}{l}-0.0068 \\
(0.0126)\end{array}$ & & $\begin{array}{l}0.125 \\
(0.131)\end{array}$ & $\begin{array}{c}0.0350 \\
(0.0399)\end{array}$ & $\begin{array}{l}0.0299 * \\
(0.0088)\end{array}$ & $\begin{array}{l}0.0210^{*} \\
(0.0082)\end{array}$ \\
\hline$\beta_{5}$ & $\begin{array}{l}-0.0303 \\
(0.0552)\end{array}$ & & $\begin{array}{l}-0.0804 \\
(0.0845)\end{array}$ & $\begin{array}{l}-0.0211 * * * \\
(-0.0256)\end{array}$ & $\begin{array}{l}-0.106^{*} \\
(0.039)\end{array}$ & $\begin{array}{l}-0.0912 * * * \\
(-0.0371)\end{array}$ \\
\hline$\beta_{6}$ & $\begin{array}{l}-0.0081^{*} \\
(0.0038)\end{array}$ & $\begin{array}{l}-0.0054^{*} \\
(0.0018)\end{array}$ & $\begin{array}{l}-0.0061^{*} \\
(0.0024)\end{array}$ & $\begin{array}{l}-0.0049 * \\
(0.0020)\end{array}$ & $\begin{array}{l}-0.0061^{*} \\
(0.0016)\end{array}$ & $\begin{array}{l}-0.0056^{*} \\
(0.0015)\end{array}$ \\
\hline$\beta_{7}$ & $\begin{array}{c}0.00089 \\
(0.0037)\end{array}$ & & $\begin{array}{c}0.0034 \\
(0.0023)\end{array}$ & & $\begin{array}{l}-0.0023 \\
(0.0016)\end{array}$ & \\
\hline Distance ${ }^{a}$ & 115.13 & 123.76 & 115.13 & 123.76 & 115.13 & 123.76 \\
\hline SSRb & 0.114 & 0.112 & 0.0710 & 0.0754 & 0.0592 & 0.0642 \\
\hline $\mathrm{R}^{2}$ & 0.265 & 0.273 & 0.525 & 0.496 & 0.558 & 0.521 \\
\hline DWc & 1.775 & $1: 829$ & 2.089 & 1.925 & 2.015 & 1.844 \\
\hline
\end{tabular}

Notes

Sample is 1975:1 TO 1988:1 (53 observations). Standard errors are in parentheses.

* Significant at the $95 \%$ level.

** Significant at the $90 \%$ level.

*** Restricted to equal $-\beta_{2}$.

a Minimum distance criterion (SSR after regressors are fitted on instruments).

b Sum of squared residuals.

c Durbin Watson statistic. 
TABLE 5: 3SLS ESTIMATES LONG-RUN EQUATION

U. $\mathbf{K}$.

$$
\begin{array}{r}
\Delta \operatorname{lns} s_{l}=\Delta\left(\ln w_{l}^{*}-\ln p_{t}\right)+1.881 \Delta\left(\ln q_{t}-\ln p_{t}\right)-0.0055 \sigma_{\varepsilon, l}^{2} \\
(0.487)
\end{array}
$$

JAPAN

$$
\ln s_{t}=\left(\ln w_{t}^{*}-\ln p_{\nu}\right)+1.660\left(\ln q_{l}-\ln p_{l}\right)-0.231 \sigma_{\varepsilon, l}^{2}
$$

GERMANY

$$
\begin{aligned}
\ln s_{t}=\left(\ln w_{t}^{*}-\ln p_{\mathcal{J}}\right) & +0.230\left(\ln q_{t}-\ln p_{\mathcal{J}}-0.0613 \sigma_{\varepsilon, \mathrm{t}}^{2}\right. \\
(0.0128) & (0.0030)
\end{aligned}
$$

\section{IMPLIED PASS-THROUGH EQUATION}

U. K.

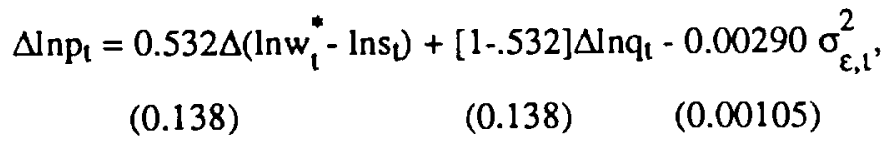

JAPAN

$$
\begin{aligned}
\ln p_{l}= & 0.602\left(\ln w_{t}^{*}-\ln s_{t}\right)+[1-0.602] l n q_{t}-0.139 \sigma_{\varepsilon, 1}^{2} . \\
(0.061) & (0.061)
\end{aligned}
$$

GERMANY

$$
\begin{aligned}
& \ln p_{t}=4.34\left(n n w_{l}^{*}-\ln s_{l}\right)+[1-4.34] \ln q_{t}-0.266 \sigma_{\varepsilon, l}^{2} . \\
& \text { (0.412) } \\
& \text { (0.412) (0.118) }
\end{aligned}
$$




\section{APPENDIX ON DATA SOURCES}

\section{A. Data for ARCH Estimates of Exchange-Rate Volatility}

The spot and 1 month forward exchange rates for the British pound, Japanese yen, and German deutschemark (day 7, 14, 21, and 28) are from the Wall Street Journal. "The New York selling rates apply to trading among banks in amounts of US\$1 million and more, as quoted at 3:00 PM Eastern time by Banker's Trust Company..." The data alignment problem has been treated in a consistent manner. The spot transactions in foreign exchange markets are for the value date two business days following the transactions days. Also, n-day forward contracts are for delivery ndays after the spot value date; the relevant future spot rate for this forward contract is contracted two business days before the forward value date. If the delivery date falls on a U.S. holiday or weekend, it takes place the next business day .

\section{B. Data Sources: Import Price Index}

Sources for import price index construction are the Citibase tape file and various issues of Survey of Current Business. Imports are given in both current and constant (1980) US dollars on a quarterly basis from 1967.I to 1988.I Implicit prices are derived by dividing current by constant dollar imports. A Divisia import price index was constructed from the following categories:

(1) Industrial supplies and materials excluding petroleum, (a) Durable and (b) Nondurable goods;

(2) Capital goods, except autos; (3) Consumer Goods, (a) Durable and (b) Nondurable goods;

(5) Other Goods, (a) Durable and (b) Nondurable goods.

\section{Data Sources: Pass-Through Equations}

Domestic price, money, income, and exchange-rate indices are from IFS Statistics for 1967.I to 1988.I. The domestic price index in from line 63 - Wholesale Prices (industrial Output Price for UK); the money supply is from line 34; real GNP is from line 99a.r (real GDP for UK, line $99 \mathrm{~b} . \mathrm{p})$; and the exchange rates are period averages (rh). 


\section{REFERENCES}

Akhtar, M.A. and R. Spence Hilton. "The Effects of Exchange Rate Uncentainty on German and U.S. Trade." Eederal Reserve Bank of New York. Ouarterly Review. 14, 1984, 7-16.

Baillie, Richard T., and Tim Bollerslev. The Message in Daily Exchange Rates: A Conditional Variance Tale. July 1987, Econometrics and Economic Theory Paper No. 8702, Michigan State Univerisity.

Baillie, Richard T. and Tim Bollerslev. A Multivariate Generalized ARCH Approach to Modeling Risk Premia in Forward Exchange Rate Markets. September 1987, Manuscript.

Baron, David P. Flexible Exchange Rates, Forward Markets, and the Level of Trade. American Economic Review 66, March 1976a, 253-266.

Baron, David P. Fluctuating Exchange Rates and the Pricing of Exports. Economic Inquiry 14, September 1976b, 425-438.

Berndt, Ernst K., B.H. Hall, R.E. Hall, and J.A. Hausman. Estimation Inference in Nonlinear Structural Models. Annals of Economic and Social Measurment 4, 1974, 653-665.

Bollerslev, Tim. Generalized Autoregressive Conditional Heteroskedasticity. Journal of Econometrics 31, April 1986, 307-327.

Cushman, David O. The Effects of Real Exchange Rate Risk on International Trade. Journal of International Economics; August 1983; 15(1/2): 45-63.

Cushman, David O. Has Exchange Risk Depressed International Trade? The Impact of ThirdCountry Exchange Risk. Joumal of Intemational Money and Finance; September 1986; 5(3): $361-379$.

Domowitz, Ian, and Craig S. Hakkio. Conditional Variance and the Risk Premium in the Foreign Exchange Market. Journal of International Economics 19, August 1985, 47-66.

Eldor, Rafael and Itzhak Zilcha. Discriminating Monopoly, Forward Markets and International Trade. International Economic Review 28(2), June 1987, 459-468.

Engle, Robert F., David M. Lilien, and Russell P. Robins. Estimating Time Varying Risk Premia in the Term Structure: The ARCH-M Model. Econometrica 55(2), March 1987, 391-407.

Engle, Robert F. and Tim Bollerslev. Modelling the Persistence of Conditional Variances. Econometric Reviews 5(1), 1986, 1-50.

Ethier, Wilfred. International Trade and the Forward Exchange Market. American Economic Review 63(3), June 1973, 494-503.

Feenstra, Robert C. Symmetric Pass-Through of Tariffs and Exchange Rates Under Imperfect Competition: An Empirical Test. Joumal of Intemational Economic 27, 1989, 25-45.

Frenkel, Jacob A. The Collapse of Purchasing Power Parities During the 1970's. European Economic Review 16(1), May 1981, 145-165. 
Gallant, A. Ronald and Dale Jorgenson. Statistical Inference for a System of Simultaneous Nonlinear, Implicit Equations in the Context of Instrumental Variable Estimation. Joumal of Econometrics 11, 1979, 275-302.

Giovannini, Alberto. Exchange Rates and Traded Goods Prices. Joumal of Intemational Economics 24, 1988, 45-68.

Gotur, Padma. Effects of Exchange Rate Volatility on Trade. IMF Staff Papers 32(3), September $1985,475-512$.

Grassman, Sven. Currency Distribution and Forward Cover in Foreign Trade: Sweden Revisited, 1973. Journal of International Economics 6(2), May 1976, $215-221$.

Grassman, Sven. A Fundamental Symmetry in International Payment Patterns. Jounal of International Economics 3(2), May 1973, 105-116.

Hakkio, Craig S. A Re-Examination of Purchasing Power Parity: A Multi-Country and MultiPeriod Study. Loumal of Intemational Economics 17(3/4), November 1984, 265-277.

Hanson, Lars P. and Hodrick, Robert J. (1980), "Forward Exchange Rates as Optimal Predictors of Future Spot Rates: An Econometric Analysis", Journal of Political Economy 88(5), 829853.

Hendry, David F. The Simple Analytics of Single Dynamic Econometric Equations, April 1980, mimeo, London School of Economics.

Hendry, D.F. Adrian R. Pagan, and J. Denis Sargan. Chapter 18 Dynamic Specification. Griliches, Zvi and Michael D. Intriligator, Editors. Handbook of Econometrics, Volume II. Amsterdam: North Holland; 1984: 1025-1100.

Hodrick, Robert J. (1989), "Risk, Uncertainty, and Exchange Rates", Journal of Monetary Economics, 23, 433-459.

Hoover, Kevin D. On the Piffalls of Untested Common-Factor Restrictions: The Case of the Inverted Fisher Hypothesis. Oxford Joumal of Economics and Statistics 50(2), June 1988, 125-138.

Hooper, Peter and Stephen Kohlhagen. "The Effect of Exchange Rate Uncertainty on the Prices and Volume of International Trade." Joumal of International Economics 8, 1978, 483511.

Hsieh, David A. The Statistical Properties of Daily Foreign Exchange Rates: 1974-1983. Joumal of International Economics 24, 1988, 129-145.

Kaminsky, Graciela Laura and Rodrigo Peruga. Can a Time-Varying Risk Premium Explain Excess Returns in the Forward Market for Foreign Exchange? Journal of Intermational Economics 28, 1990, 47-70.

Kawai, Masashiro and Itzhak Zilcha. International Trade with Forward-Futures Markets under Exchange Rate Uncertainty. Joumal of Intemational Economics 20, February 1986, 83-98.

Krugman, Paul R. Exchange Rate Instability. Cambridge, MA: MIT Press, 1989. 
Mann, Catherine L. The Effects of Exchange-Rate Trends and Volatility on Export Prices: Industry Examples from Japan, Germany, and the United States. Weltwinschafiliches Archiv 125(3), 1989, 588-618.

Meese, Richard A. and Kenneth J Singleton. On Unit Roots and the Empirical Modeling of Exchange Rates. The Joumal of Finance 37(4), September 1982, 1029-1035.

Page, Mrs. S. A. B. The Choice of Invoicing Currency in Merchandise Trade, National Institute Economic Review, No. 98, 1981.

West, Kenneth D. A Standard Monetary Model and the Variability of the Deutschemark-Dollar Exchange Rate. Joumal of International Economics 23(1/2), August 1987, 57-76.

Woo, Wing T. The Monetary Approach to Exchange Rate Determination Under Rational Expectations. Joumal of International Economics 18, 1985, 1-16. 


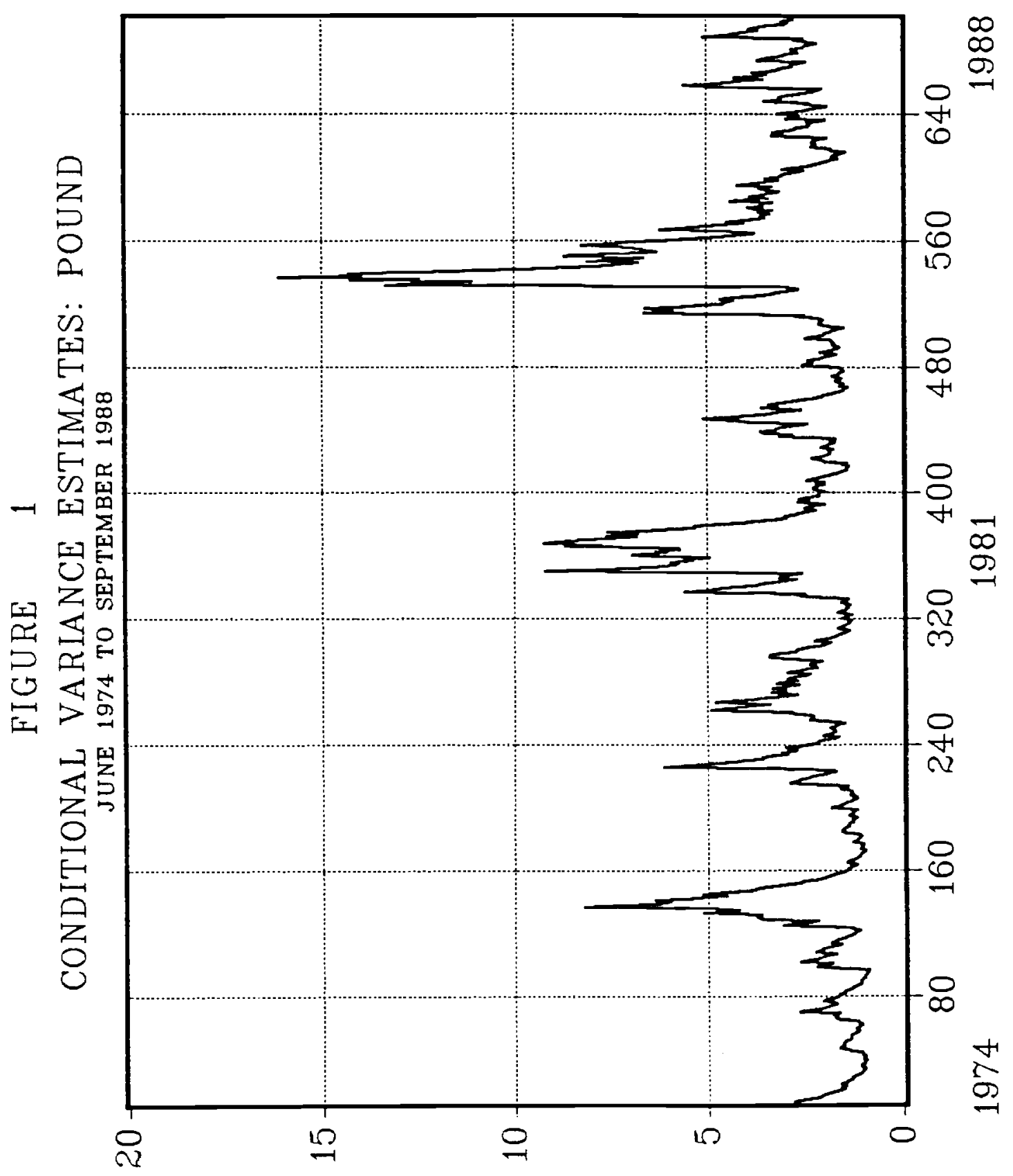




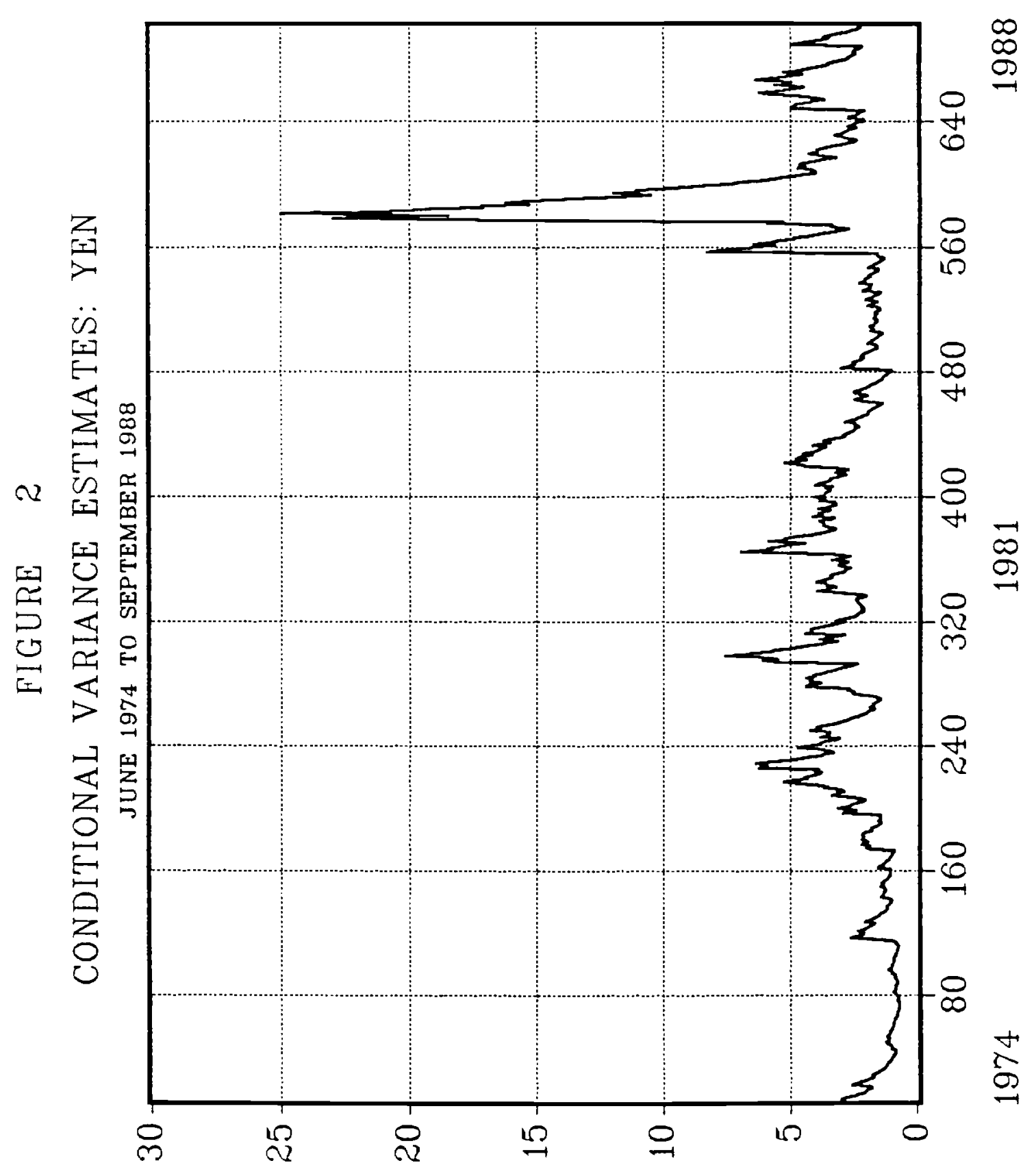




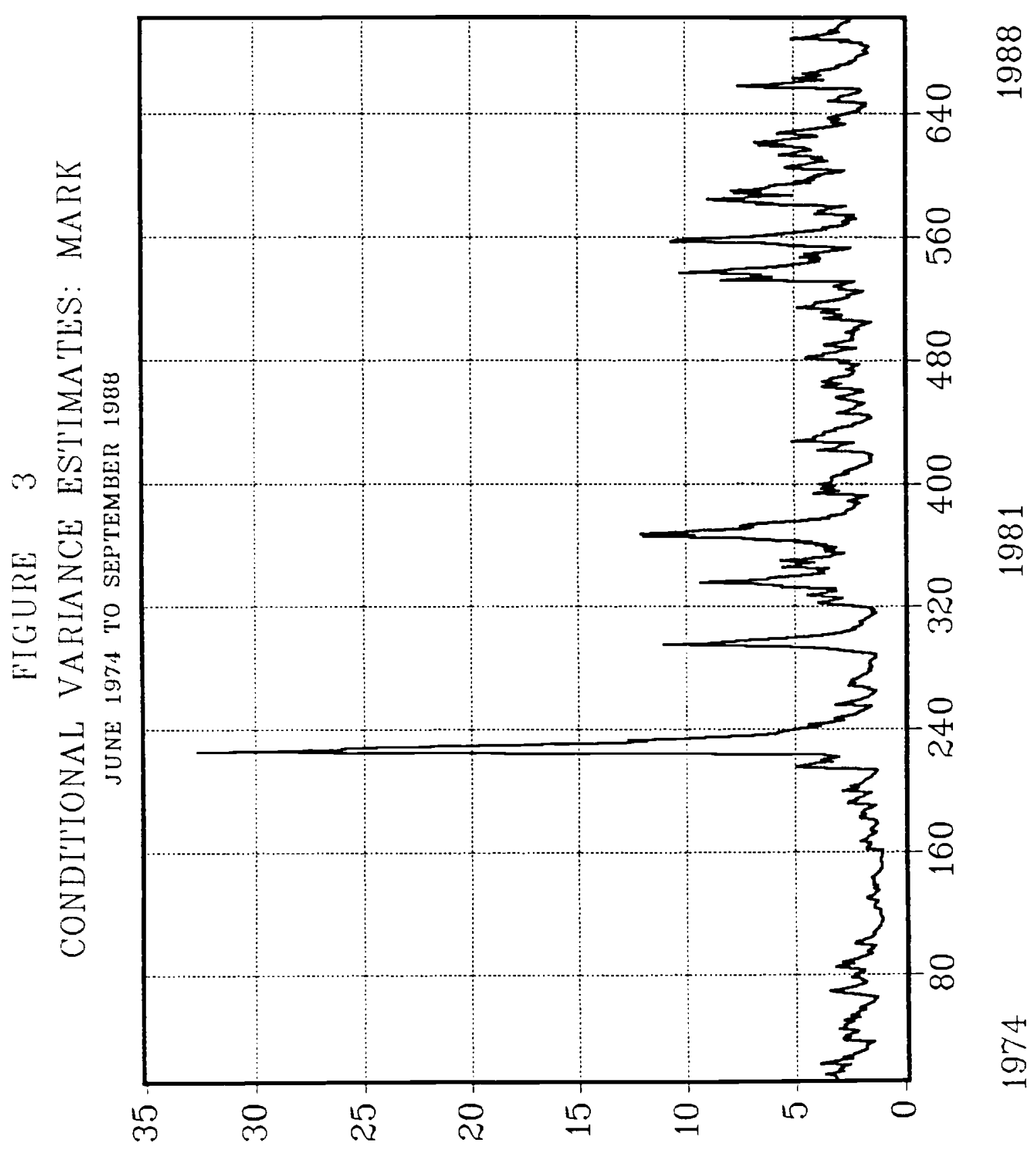




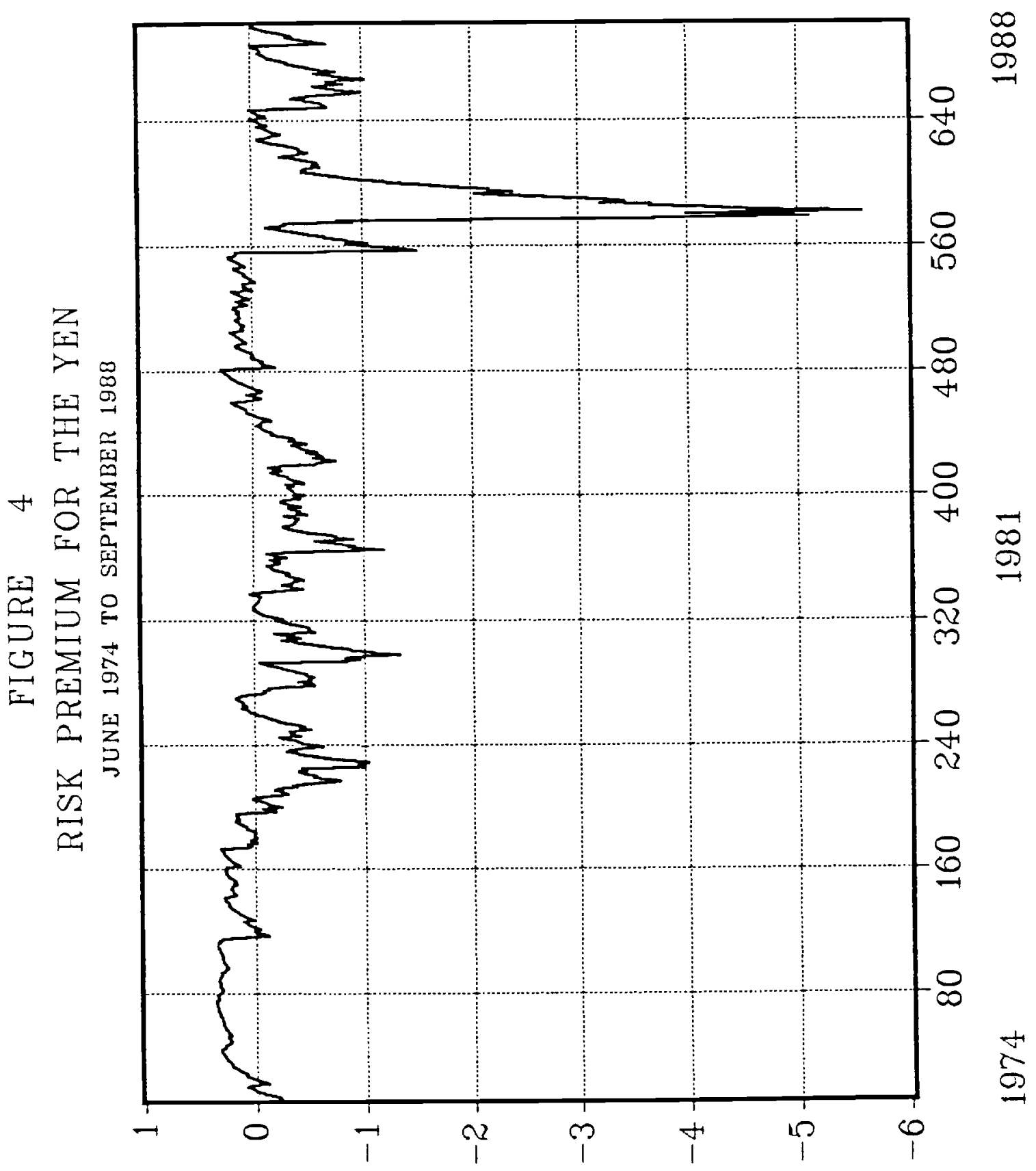

